\title{
Synthesis of spoIIA and spoVA mRNA in Bacillus subtilis
}

\author{
By D. SAVVA ${ }^{1,2}$ AND J. MANDELSTAM ${ }^{1 *}$ \\ ${ }^{1}$ Microbiology Unit, Department of Biochemistry, University of Oxford, South Parks Road, \\ Oxford OX1 2QU, UK \\ ${ }^{2}$ Department of Physiology and Biochemistry, University of Reading, Whiteknights, \\ Reading RG6 $2 A J, U K$
}

(Received 11 March 1986; revised 30 May 1986)

\begin{abstract}
The expression of the spoIIA and spoVA sporulation loci of Bacillus subtilis was examined by using DNA-RNA hybridization to detect the time of appearance of their corresponding mRNA molecules in wild-type and asporogenous mutants of $B$. subtilis. From the size of the mRNA molecules it is clear that both the spoIIA and spoVA loci are polycistronic operons. Neither of the mRNA molecules is polyadenylated. The results also indicate the spoIIA operon is regulated by two promoters which become functional at different times.
\end{abstract}

\section{INTRODUCTION}

Sporulation in Bacillus subtilis is determined by over 50 identified operons (Piggot \& Hoch, 1985), and the means by which they are regulated remains an unsolved problem, though several models have been proposed. Among these is the suggestion that they are expressed in a linear dependent sequence in which one of the translational products of each operon induces or derepresses the next (Mandelstam, 1969, 1976). In variants of this model the possibilities have been considered that there are parallel or branched sequences (Coote \& Mandelstam, 1973; Piggot \& Coote, 1976). In a rather different model it has been proposed that the sequence is regulated by successive replacements of the sigma factor of RNA polymerase (see Losick \& Pero, 1981; Westpheling et al., 1985). Some involvement of sigma factors in sporulation is also supported by the report (Trempy et al., 1985) that the spoIIG locus in B. subtilis has a region of close homology with the $E$. coli rpoD gene, which encodes a sigma factor. An equally intriguing observation followed from the sequence determination of spoIIA (Fort \& Piggot, 1984), which showed that the locus contains three genes. It is now apparent that the third of these genes, 'ORF 3', has a striking similarity both to spoIIG in B. subtilis and to the rpoD gene of E. coli already referred to (Errington et al., 1985).

Clearly, further facts are needed before we can make any choice between these models and others that can easily be suggested. The work described here was undertaken to examine the expression of the spoIIA and spoVA loci, which have been cloned and sequenced recently (Savva \& Mandelstam, 1984; Fort \& Piggot, 1984; Fort \& Errington, 1985). We used portions of both operons to determine transcription in a number of sporulation mutants. These results were published in a preliminary form (Savva \& Mandelstam, 1985). Here we report the results for 14 additional mutants and show that the two transcripts have markedly different half-lives.

\section{METHODS}

Bacterial strains. The strains used in this investigation are shown in Table 1 of an accompanying paper (Errington \& Mandelstam, 1986a), except for strains 69 (trpC2 spoIIA69) [strain NG18.6 of Piggot (1973)], 487 (trpC2 phe A12 spo0C9) [strain 9V of Ionesco et al. (1970)] and SL980(trpC2 metB10 spoIIA4) (Liu et al., 1982). Bacteria were grown and resuspended in sporulation medium as described by Sterlini \& Mandelstam (1969); at different times after resuspension, samples $(100 \mathrm{ml})$ of culture were removed and used for the isolation of RNA. All experiments were done at $37^{\circ} \mathrm{C}$, and the time (h) after resuspension is denoted $t_{0}, t_{1}$, etc. 
Buffer and other solutions. The following solutions were used: (i) lysozyme [ $1 \%(\mathrm{w} / \mathrm{v})$ in $50 \mathrm{mM}-\mathrm{Tris} / \mathrm{HCl} \mathrm{pH} 8 \cdot 0]$; (ii) guanidinium isothiocyanate [6 $\mathrm{M}$-guanidinium isothiocyanate, $0 \cdot 1 \mathrm{M}$ - $\beta$-mercaptoethanol, $5 \mathrm{~mm}$-sodium citrate pH 7.0, 0.5\% (w/v) sarcosyl]; (iii) RNA loading buffer [20\% (w/v) glycerol, $50 \mathrm{~mm}$-boric acid, $5 \mathrm{~mm}$-sodium tetraborate, $10 \mathrm{~mm}$-sodium sulphate, $25 \mathrm{~mm}$-methyl mercuric hydroxide, $0.02 \%$ (w/v) bromophenol blue]; (iv) gelrunning buffer ( $50 \mathrm{~mm}$-boric acid, $5 \mathrm{~mm}$-sodium tetraborate, $10 \mathrm{~mm}$-sodium sulphate); (v) SSC ( $0 \cdot 15 \mathrm{M}-\mathrm{NaCl}$, $0.015 \mathrm{M}$-sodium citrate, $\mathrm{pH} 7.0)$; (vi) prehybridization solution [ $50 \%(\mathrm{v} / \mathrm{v})$ formamide, $0.9 \mathrm{M}-\mathrm{NaCl}, 5 \mathrm{~mm}$-EDTA (disodium salt), $50 \mathrm{~mm}$-sodium phosphate buffer $\mathrm{pH} \mathrm{7.7,0.1 \% (w/v)} \mathrm{sodium} \mathrm{dodecyl} \mathrm{sulphate,} 0.02 \%(\mathrm{w} / \mathrm{v})$ bovine serum albumin, $0.02 \%(\mathrm{w} / \mathrm{v})$ Ficoll, $0.02 \%(\mathrm{w} / \mathrm{v})$ polyvinylpyrrolidone, $0.01 \%(\mathrm{w} / \mathrm{v})$ denatured salmon sperm DNA]; (vii) wash solution 1 [0.36 M- NaCl, 2 mM-EDTA (disodium salt), $20 \mathrm{~mm}$-sodium phosphate buffer pH 7.7, $0 \cdot 1 \%(\mathrm{w} / \mathrm{v})$ sodium dodecyl sulphate]; (viii) wash solution 2 [0.018 $\mathrm{M}-\mathrm{NaCl}, 0 \cdot 1 \mathrm{~mm}$-EDTA (disodium salt), $1 \mathrm{~mm}$ sodium phosphate buffer $\mathrm{pH} 7 \cdot 7,0 \cdot 1 \%(\mathrm{w} / \mathrm{v})$ sodium dodecyl sulphate].

Isolation, electrophoresis and blotting of RNA. The methods used were those described by Savva \& Mandelstam (1985), as were the procedures for DNA-RNA hybridizations. The specific activity of the probe DNA was 1$5 \times 10^{7}$ c.p.m. per $\mu \mathrm{g}$ DNA.

Isolation of polyadenylated RNA. RNA $(0.5 \mathrm{mg})$ isolated from $B$. subtilis 168 at $t_{5}$ after resuspension was separated into the polyadenylated (poly- $A^{+}$) and non-polyadenylated (poly- $A^{-}$) fractions using oligo-dT-cellulose chromatography (Aviv \& Leder, 1972). The procedure used was that described by Maniatis et al. (1982) for batch absorption and elution of RNA.

Electrophoresis of DNA and isolation of restriction fragments from agarose gels. Restriction enzyme reaction, electrophoresis of DNA and isolation of DNA restriction fragments from agarose gels were done as described by Savva \& Mandelstam (1984).

\section{RESULTS}

\section{Hybridization probes}

The isolation of the recombinant phage $\phi 105 \mathrm{DS} 1$ (derived from phage $\phi 105$ ), which contains the B. subtilis spoIIA and spoVA loci, has been reported earlier (Savva \& Mandelstam, 1984).

By using the DNA sequences of the spoIIA and spoVA loci (Fort \& Piggot, 1984; Fort \& Errington, 1985), a number of DNA restriction fragments which lie totally within each locus were chosen, isolated from low melting point agarose gels, labelled by nick translation (Rigby $e t$ $a l ., 1977)$ and used as probes for the detection of the transcripts of these loci. Fig. 1 shows the restriction fragments used as probes for the detection of the spoIIA and the spoVA mRNA molecules; these were the $0.67 \mathrm{~kb} E c o \mathrm{RI}-B g / \mathrm{II}$ and the $1.89 \mathrm{~kb} E c o \mathrm{RV}-E c o \mathrm{RV}$ fragments respectively. Identical results were obtained with a number of other probes in each locus (data not shown).

\section{Times of transcription of spoII $A$ and spoVA}

Samples of RNA $(4 \mu \mathrm{g})$ isolated from wild-type $B$. subtilis at different times after resuspension in sporulation medium were spotted on each of two nitrocellulose filters and hybridized to either the spoIIA probe or the spoVA probe (Fig. 2). Both probes failed to hybridize to the RNA samples isolated immediately after resuspension in the sporulation medium (i.e. at $t_{0}$ ); this indicates that transcription of both the spoIIA and the spoVA loci does not occur during vegetative growth.

The spoIIA probe was found to hybridize to the RNA samples isolated $1 \mathrm{~h}$ or more after resuspension (i.e. $t_{1}-t_{5}$ samples). However, at $t_{1}$ the hybridization was weak, indicating that the amount of spoIIA mRNA was low. In the case of the spoVA probe, weak hybridization was obtained with the RNA sample isolated at $t_{3}$, with signals becoming more intense at $t_{4}$ and $t_{5}$. (Results, not shown indicated that at $t_{3 \cdot 5}$ the hybridization signal was as strong as at $t_{4}$.) Therefore, it appeared that the transcripts for spoIIA and spoVA began to be synthesized at about $t_{1}$ and $t_{3}$ respectively, and that both transcripts were present until at least $t_{5}$.

The more informative and reliable method of 'northern' hybridizations on gels confirmed these results (Fig. 3) and provided further information about the spoIIA and spoVA mRNA molecules. Initially, the spoIIA probe hybridized to only one mRNA species, the size of which, about $1.7 \mathrm{~kb}$, was in agreement with the results of Fort \& Piggot (1984) which showed that the spoIIA locus is a polycistronic operon. However, from $t_{3}$ onwards the spoIIA probe hybridized to a second, larger species of mRNA of about $2.6 \mathrm{~kb}$ (Fig. 3). As the spoVA probe did not hybridize 


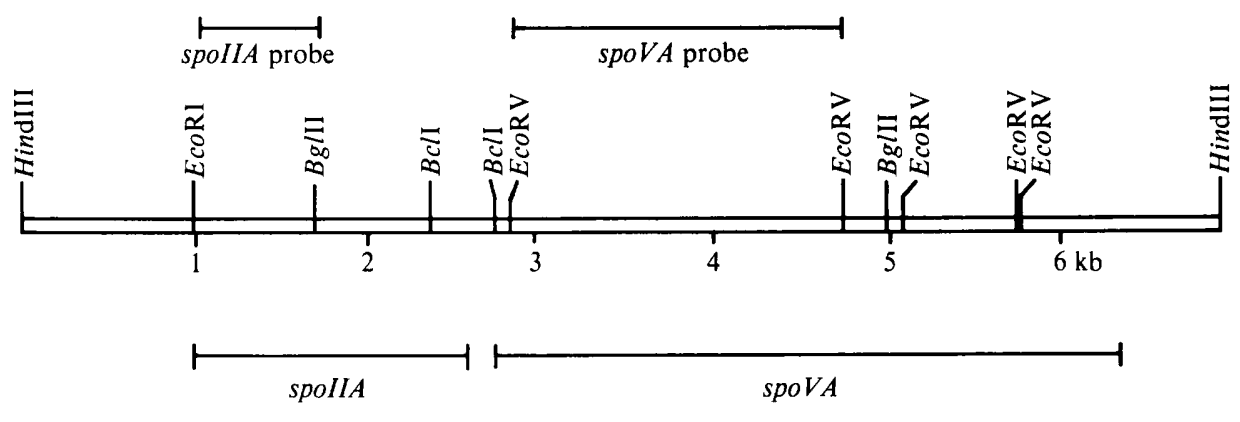

Fig. 1. Genetic map of the cloned $B$. subtilis DNA based on the DNA sequence of the spoIIA and spoVA loci (Fort \& Piggot, 1984; Fort \& Errington, 1985). The DNA restriction fragments used as probes in the hybridization experiments and some restriction enzyme cleavage sites are shown.
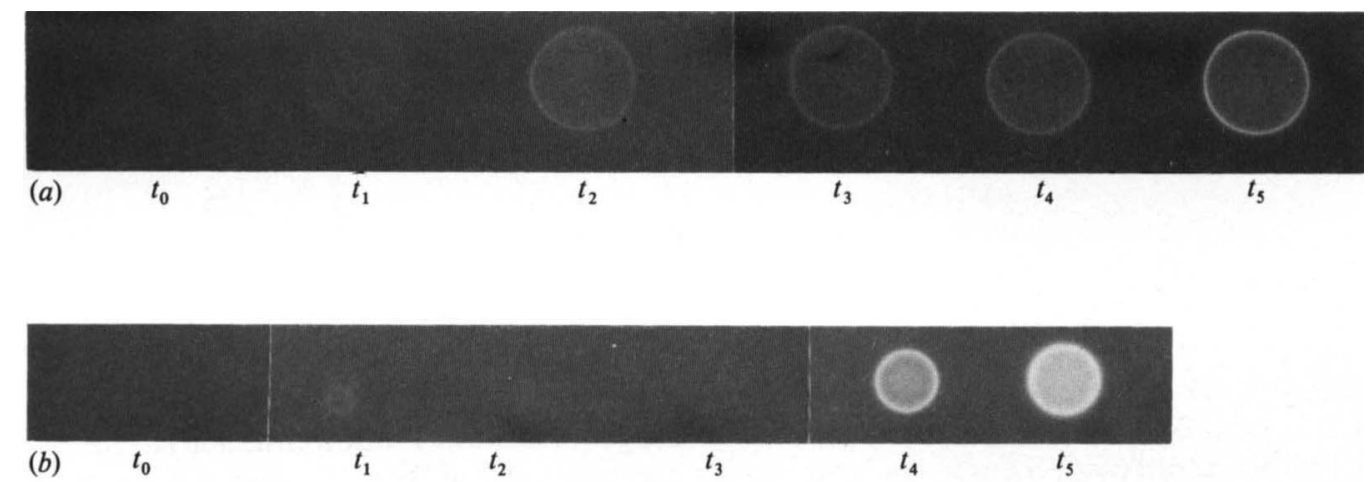

Fig. 2. Timing of transcription of the (a) spoIIA and (b) spoVA loci as determined by dot hybridizations. Samples labelled $t_{0}-t_{5}$ were isolated at the indicated time (h) after resuspension of $B$. subtilis 168 .

to this mRNA species, this larger transcript was not the result of anti-termination of spoIIA transcription.

In the case of the spoVA mRNA, the exact size could not be determined because of the smearing of the RNA samples due, presumably, to degradation of this much larger mRNA species during preparation.

\section{Stability of the $M R N A$ transcribed from spoIIA and spoVA}

$B$. subtilis 168 was resuspended in sporulation medium and incubated at $37^{\circ} \mathrm{C}$ for $4 \mathrm{~h}$ before actinomycin D was added to a final concentration of $1 \mu \mathrm{g} \mathrm{ml}^{-1}$. Samples of culture were removed immediately and after 3,6 and $9 \mathrm{~min}$, and were used for isolation of RNA as described in Methods. These RNA samples were used in dot hybridizations with the two probes. The results (Fig. 4) show that a 3 min treatment with actinomycin D causes a considerable reduction in the amount of the spoIIA mRNA; this suggests that the spoIIA mRNAhas a short half-life (possibly 2-3 min). However, the spoVA mRNA appeared to be more stable since it was still detectable even after 9 min of treatment with actinomycin D. Identical results were obtained using 'northern' hybridization analysis (results not shown).

\section{Polyadenylated RNA}

Total RNA from $B$. subtilis 168 was separated into a poly- $\mathrm{A}^{+}$and a poly- $\mathrm{A}^{-}$fraction by oligodT-cellulose chromatography; the amount of poly- $A^{+}$RNA (as estimated on agarose gels after staining with ethidium bromide) was about $5 \%$ of the total (results not shown). 
(a)

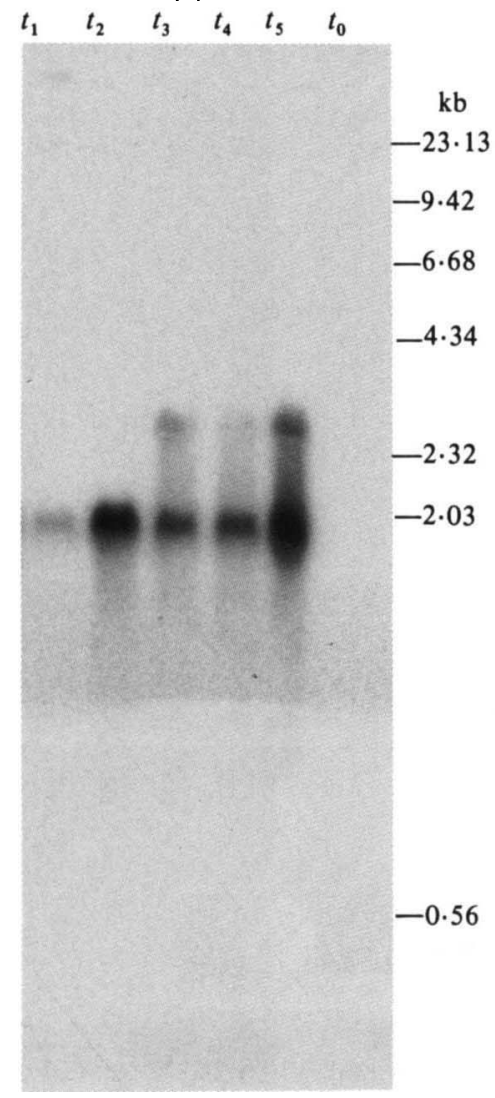

(b)

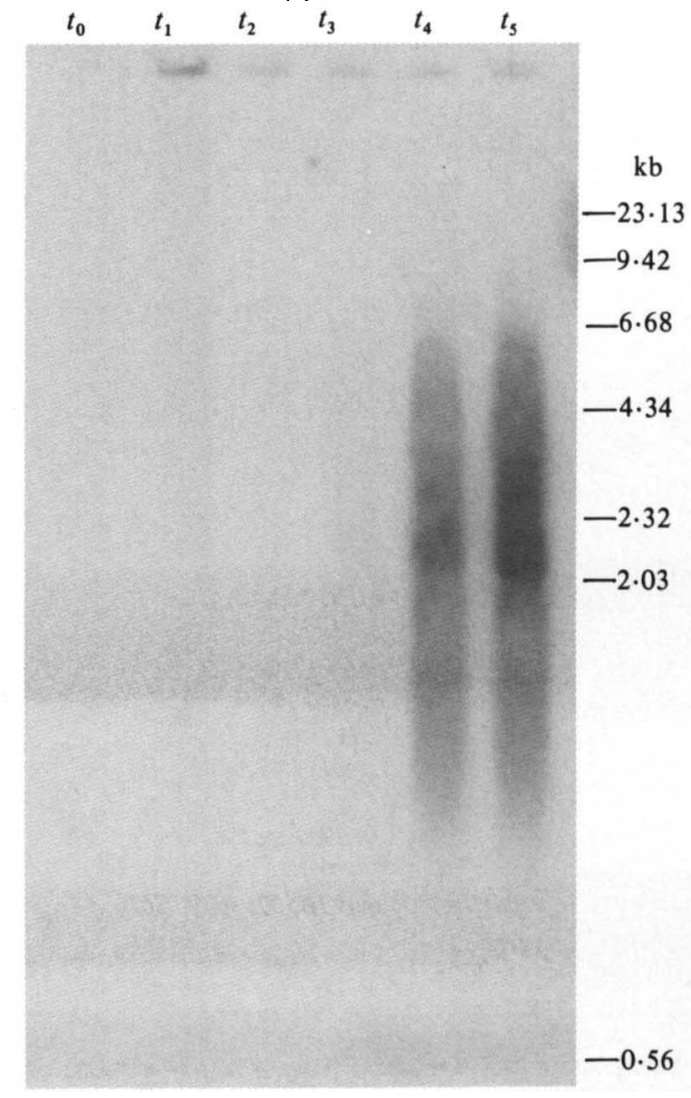

Fig. 3. 'Northern' hybridizations for the detection of (a) spoIIA mRNA and (b) spoVA mRNA. Samples labelled $t_{0}-t_{5}$ were isolated at the indicated time (h) after resuspension of $B$. subtilis 168 . The origin is at the top of the figure. The positions of the size markers used (phage $\lambda$ cleaved with HindIII) are indicated.
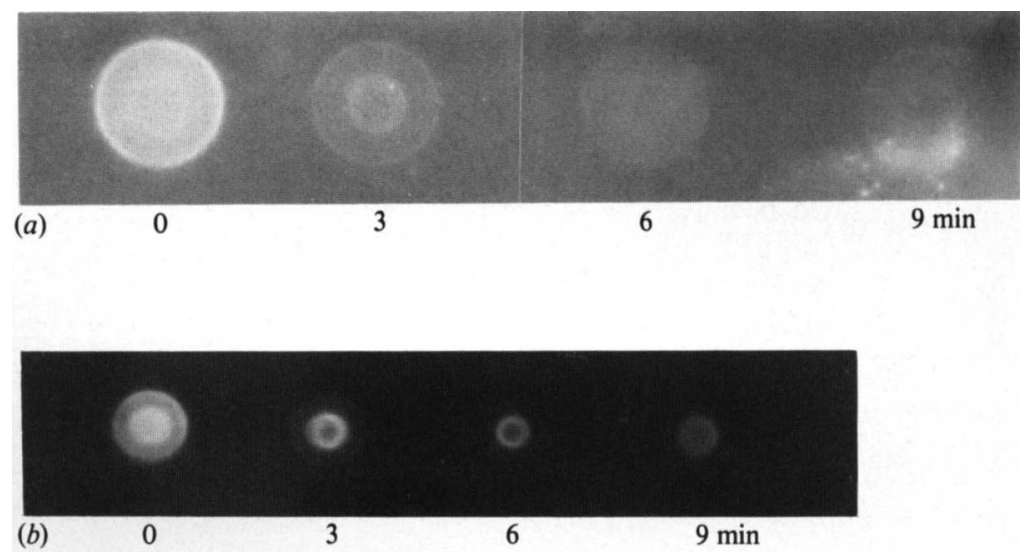

Fig. 4. Dot hybridizations showing the stability of the transcripts of the (a) spoIIA and $(b)$ spoVA loci. Actinomycin D $\left(1 \mu \mathrm{g} \mathrm{ml}^{-1}\right)$ was added to $B$. subtilis 168 at $t_{4}$ and RNA was isolated after $0,3,6$ and $9 \mathrm{~min}$. 
Table 1. Transcription of the spoIIA and spoVA loci in asporogenous mutants of $B$. subtilis

The spoIIA and spoVA probes were hybridized to the $t_{2 \cdot 5}$ and $t_{5}$ RNA samples respectively; both probes were also hybridized to a $t_{0}$ sample of RNA from each strain and in every case no hybridization occurred. +, Hybridization; -, no hybridization; w, weak hybridization ( $<10 \%$ of normal strength). Where a signal of intermediate strength was obtained this is expressed as a percentage of the normal strength.

Mutation
spo0A43
spo0B136, spo0C9, spo0D486
spo0E11
spo0F 221, spo0G485, spo0H17
spo0J93
spo0K141
spoIIA4
spoIIA69, spoIIB131, spoIID298,
spoIIE48, spoIIG55
spoIIIA65, spoIIIB2, spoIIIC496,
spoIIID497, spoIIIE36, spoIIIF590
spoIVA67, spoIVB165, spoIVC23,
spoIVD92, spoIVE498, spoIVF88,
spoIVG25
spoVA89, spoVB91, spoVC134,
spoVD156, spoVE85, spoVF 224
spoVIA513, spoVIB520, spoVIC610
gerE36

$\begin{array}{cc}\begin{array}{c}\text { spoIIA } \\ \text { probe } \\ 10-15 \% \\ \text { w } \\ 10-15 \% \\ \text { w }\end{array} & \begin{array}{c}\text { spoVA } \\ \text { probe }\end{array} \\ 10-15 \% & \text { w } \\ \text { w } & - \\ - & \text { w } \\ + & - \\ + & \text { w } \\ + & \text { w } \\ + & \text { w } \\ + & + \\ + & +\end{array}$

Samples of poly- $\mathrm{A}^{+}$and poly-A- $\mathrm{A}^{-}$RA were used in dot hybridizations with the spoIIA and spoVA probes. Neither probe hybridized to the poly-A+ RNA fraction (results not shown), so apparently the mRNA molecules for spoIIA and spoVA were not polyadenylated.

\section{Transcription of the spoIIA and spoVA operons in asporogenous mutants blocked at various stages of sporulation}

The transcription of the spoIIA operon in a number of asporogenous mutants of $B$. subtilis was studied by hybridizing the spoIIA probe to RNA isolated from these mutants $2.5 \mathrm{~h}$ after resuspension; both dot and 'northern' hybridizations were used. Similar experiments were done using the spoVA probe but the RNA samples were isolated $5 \mathrm{~h}$ after resuspension. For both probes RNA samples isolated from each mutant at $t_{0}$ were also used.

The results of these hybridizations are shown in Table 1. It is apparent that neither the spoIIA probe nor the spoVA probe hybridized to the RNA isolated from the spoIIA4 mutant (strain SL980). This was expected because DNA from this strain shows no homology to plasmids pHM2 (Liu et al., 1982) and pPP33 (Piggot et al., 1984) and therefore the whole of the spoIIA operon and most of the spoVA must be deleted (P. Piggot, personal communication).

Transcription of the spoIIA operon was found to occur in all the stage 0 mutants investigated but the amount of the spoIIA mRNA was different in different mutants. In the case of $s p o 0 B$, spo0C, spoOD, spoOF, spoOG, spoOH and spoOK only trace amounts of spoIIA mRNA were observed, whilst $s p o 0 A$, spoOE and spoOJ produced markedly higher amounts, which were roughly judged to be $10-15 \%$ of normal. All the mutants tested which were blocked at stage II or later, apart, of course, from the spoIIA4 strain, were found to produce normal amounts of spoIIA mRNA.

The spoVA probe did not hybridize to the RNA samples isolated from most stage 0 mutants; however, trace amounts of spoVA mRNA were observed in $s p o 0 A, s p o 0 E$ and spo0J mutants. Traces of spoVA mRNA were also found in all the stage II and stage III mutants examined. 
Transcription of the spoVA operon was found to be normal in the stage IV, stage V, stage VI and ger $E$ mutants investigated.

Neither probe hybridized to the RNA isolated from the mutants tested at $t_{0}$. For a number of mutants the time of transcription was also determined; in these cases, transcription of both operons was found to occur at the same time as in the wild-type strain (results not shown).

\section{DISCUSSION}

Although the spoIIA and spoVA operons are closely linked and have been cloned as a single insert in phage $\phi 105$ (Savva \& Mandelstam, 1984), they are transcribed at quite different times. The mRNA corresponding to spoIIA becomes detectable at $t_{1}$ and the signal in 'northern' blot experiments is at full strength by $t_{1.5}$. The transcript is roughly $1.7 \mathrm{~kb}$ in size, which is what would be expected if the three genes of spoIIA, coding for a total of 507 amino acid residues (divided between three polypeptides) (Fort \& Piggot, 1984), gave rise to a single polycistronic message. An unexpected finding was the appearance at $t_{3}$ of a second and larger species of mRNA molecule (about $2.6 \mathrm{~kb}$ ) which also hybridized with the spoIIA probe (see Fig. 3 ). This observation remained puzzling until S1 nuclease studies indicated the presence of a second promoter about $1 \mathrm{~kb}$ upstream from the first (D. Savva, unpublished); it therefore seems likely that at $t_{3}$ transcription of the operon starts from this second promoter. This may be relevant to the fact that in some strains containing the $\beta$-galactosidase gene, lac $Z$, fused into the spoIIA operon (Errington \& Mandelstam, 1986a), there is a preliminary output of $\beta$-galactosidase beginning at $t_{1}$ that reaches a plateau at about $t_{2}$ and is followed by renewed enzyme synthesis at $t_{3}$, about the time that the larger mRNA species becomes detectable.

Transcription of the spoVA operon began at $t_{3}$ and was undiminished at $t_{5}$, when the last samples were taken. Experiments with strains containing a spoVA/lacZ fusion showed that the messenger for this operon is also translated without delay (Errington \& Mandelstam, 1986 b). It is worth noting that the defect in spore development resulting from mutations in this locus only becomes manifest about $2 \mathrm{~h}$ after the appearance of the translation products. This is in keeping with the earlier findings of Dion \& Mandelstam (1980) and Jenkinson et al. (1981), which showed that the spore properties associated with stages V and VI result from the self-assembly of proteins made at earlier stages.

In view of the report (Kerjan et al., 1982) that sporulation involves the production of polyadenylated mRNA, we looked for polyadenylation in the messenger molecules for both spoIIA and spoVA and did not find it in either. It thus appears that polyadenylation is not an invariable property of sporulation mRNA molecules.

The very rough estimates of half-lives show that these are different for the two species of mRNA, being very approximately 2-3 min for spoIIA mRNA and rather longer for spoVA mRNA. It is of interest in this context that Segall \& Losick (1977) have shown that the mRNA for spoVG has an extended half-life and is detectable in quantity even after $30 \mathrm{~min}$.

The fact that some species of mRNA have fairly long half-lives, as implied by earlier experiments with actinomycin D (Sterlini \& Mandelstam, 1969), raises the possibility that translational control may be a factor in regulation of the sporulation sequence. The evidence, already cited and based on lac $Z$ fusions, that translation occurs without delay once the mRNA molecules for these two sporulation operons have been synthesised does not formally rule out the intervention of a translational control step, though it does make it less likely.

We studied the transcription of the two operons in mutants blocked at various stages; spoIIA was transcribed poorly or not at all in all the types of $s p o 0$ mutants that were tested (Table 1). By contrast, transcription at the normal rate was found in all the stage II mutants tested except for the mutant carrying spoIIA4, which is a deletion of the whole operon. Transcription also took place normally, as might have been expected, in mutants blocked at later stages. Similarly, spoV $A$ was transcribed poorly or not all in mutants blocked at stages up to and including stage III, but the transcript was found in normal amounts in all the stage IV, stage V and stage VI mutants tested in the mutant carrying gerE36.

This work was supported by the Science and Engineering Research Council (J.M.) and the Society for General Microbiology (D.S.). 


\section{REFERENCES}

Aviv, H. \& LEDER, P. (1972). Purification of biologically active globin messenger RNA by chromatography on oligothymidylic acid-cellulose. Proceedings of the National Academy of Sciences of the United States of America 69, 1408-1412.

Coote, J. G. \& Mandelstam, J. (1973). Use of constructed double mutants for determining the temporal order of expression of sporulating genes in Bacillus subtilis. Journal of Bacteriology 114, 12541263.

Dion, P. \& MandelstaM, J. (1980). Germination properties as marker events characterizing later stages of Bacillus subtilis spore formation. Journal of Bacteriology 141, 786-792.

ERrington, J. \& MANDELSTAM, J. (1986a). Use of a lac $Z$ gene fusion to determine the dependence pattern of sporulation operon spoIIA in spo mutants of Bacillus subtilis. Journal of General Microbiology 132, 2967-2976.

ERrington, J. \& MANDelstam, J. (1986b). Use of a lacZ gene fusion to determine the dependence pattern and the spore compartment expression of sporulation operon spoVA in spo mutants of Bacillus subtilis. Journal of General Microbiology 132, 29772985.

Errington, J., Fort, P. \& Mandelstam, J. (1985). Duplicated sporulation genes in bacteria: implications for simple developmental systems. FEBS Letters 188, 184-188.

ForT, P. \& ERrington, J. (1985). Nucleotide sequence and complementation analysis of a polycistronic sporulation operon, spoVA, in Bacillus subtilis. Journal of General Microbiology 131, 1091-1105.

FORT, P. \& PIGGOT, P. J. (1984). Nucleotide sequence of sporulation locus spoIIA in Bacillus subtilis. Journal of General Microbiology 130, 2147-2153.

IONESCO, H., Michel, J., CAMI, B. \& SChAEFFER, P. (1970). Genetics of sporulation in Bacillus subtilis Marburg. Journal of Applied Bacteriology 33, 13-24.

Jenkinson, H. F., SAWYeR, W. D. \& Mandelstam, J. (1981). Synthesis and order of assembly of spore coat proteins in Bacillus subtilis. Journal of General Microbiology 123, 1-16.

KerJan, P., Jayaraman, K. \& Szulmajster, J. (1982). Studies on the nature and role of polyadenylated RNA in spore development of Bacillus subtilis. Molecular and General Genetics 185, 448-453.

LiU, H.-M., ChaK, K. F. \& Piggot, P. J. (1982). Isolation and characterization of a recombinant plasmid carrying a functional part of the Bacillus subtilis spoIIA locus. Journal of General Microbiology 128, 2805-2812.

Losick, R. \& Pero, J. (1981). Cascades of sigma factors. Cell 25, 582-584.

MANDELSTAM, J. (1969). Regulation of bacterial spore formation. Symposia of the Society for General Microbiology 19, 377-402.
MANDelstaM, J. (1976) Bacterial sporulation: a problem in the biochemistry and genetics of a primitive developmental system. Proceedings of the Royal Society B193, 89-106.

MaNiATIS, T., Fritsch, E. F. \& SAMBrOOK, J. (1982). Molecular Cloning: A Laboratory Manual, pp. 196198. Cold Spring Harbor, NY: Cold Spring Harbor Laboratory.

Piggot, P. J. (1973). Mapping of asporogenous mutations of Bacillus subtilis: a minimum estimate of the number of sporulation operons. Journal of Bacteriology 114, 1241-1253.

Piggot, P. J. \& Coote, J. G. (1976). Genetic aspects of bacterial endospore formation. Bacteriological Reviews 40, 908-962.

Piggot, P. J. \& HoCH, J. A. (1985). Revised genetic linkage map of Bacillus subtilis. Microbiological Reviews 49, 158-179.

Piggot, P. J., Curtis, C. A. M. \& de Lencastre, H. (1984). Use of integrational plasmid vectors to demonstrate the polycistronic nature of a transcriptional unit (spoIIA) required for sporulation of Bacillus subtilis. Journal of General Microbiology 130, 2123-2136.

Rigby, P. W. J., Dieckmann, M., Rhodes, C. \& Berg, P. (1977). Labelling deoxyribonucleic acid to high specific activity in vitro by nick translation with DNA polymerase I. Journal of Molecular Biology 113, 237-251.

Savva, D. \& Mandelstam, J. (1984). Cloning of the Bacillus subtilis spollA and spoVA loci in phage $\phi 105 \mathrm{DI}$ : 1t. Journal of General Microbiology 130, 2137-2145.

Savva, D. \& Mandelstam, J. (1985). Use of cloned spoIIA and spoVA probes to study synthesis of mRNA in wild-type and asporogenous mutants of Bacillus subtilis. In Molecular Biology of Microbial Differentiation (Spores IX), pp. 55-59. Edited by P. Setlow \& J. A. Hoch. Washington, DC: American Society for Microbiology.

SEgALL, J. \& Losick, R. (1977). Cloned Bacillus subtilis DNA containing a gene that is activated early during sporulation. Cell 11, 751-761.

Sterlini, J. M. \& Mandelstam, J. (1969). Commitment to sporulation in Bacillus subtilis and its relationship to actinomycin resistance. Biochemical Journal 113, 29-37.

Trempy, J. E., Morrison-Plummer, J. \& HaldenWANG, W. G. (1985). Synthesis of sigma 29, an RNA polymerase specificity determinant, is a developmentally regulated event in Bacillus subtilis. Journal of Bacteriology 161, 340-346.

WestPheling, J., Ranes, M. \& Losick, R. (1985). RNA polymerase heterogeneity in Streptomyces coelicolor. Nature, London 313, 22-27. 